\title{
¿La magia suscita la investigación? Entrevista sobre el Análisis Multimodal del Discurso con la profesora e investigadora Carmen Luz Maturana
}

\author{
Carmen Luz Maturana ${ }^{\mathrm{i}}$ \\ Entrevistadores: \\ Ana Paula Macri ${ }^{\text {ii }}$ \\ Lais Alves ${ }^{\mathrm{iii}}$ \\ Thayane Verçosa ${ }^{\text {iv }}$
}

¿La magia suscita la investigación? En esta edición, Palimpsesto invita a Carmen Luz Maturana, diseñadora teatral y lingüista, a una entrevista sobre multimodalidad. Carmen Luz es Doctora en Lingüística pela Universidad Católica de Chile, profesora asistente adjunta en la Universidad Católica de Chile y docente del Programa de Lectura y Escritura Académica (PLEA) de la Facultad de Letras UC. Sus áreas de interés incluyen el Análisis del Discurso Multimodal y la Semiótica Educativa. Lideró el proyecto Incidencia de la Multimodalidad en Lectura y Escritura en la Enseñanza Básica, financiado por el Ministerio de las Culturas y las Artes de Chile (2019-2020). Sus investigaciones incluyen el teatro de sombras y los espectáculos teatrales de la era precine. En 1994, forma parte de la fundación de la compañía de

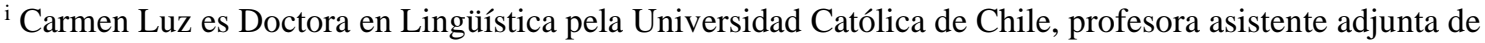
la Universidad Católica de Chile y docente del Programa de Lectura y Escritura Académica (PLEA) de la Facultad de Letras UC. Sus áreas de interés incluyen el Análisis del Discurso Multimodal y la Semiótica Educativa.

ii Estudiante de maestria en Estudios de Lengua Portuguesa en la Universidade do Estado do Rio de Janeiro (UERJ), especialista en Lengua Portuguesa en la institución Liceu Literário Português. anapaulamacri@gmail.com / http://lattes.cnpq.br/0320818365964858

iii Estudiante de maestría en Teoría de la Literatura y Literatura Comparada en la Universidad Estatal de Río de Janeiro (UERJ). Titular de beca de investigación em la institución pública financiadora CAPES. lais.alvessouza@yahoo.com.br

iv Estudiante de Doctorado en Literatura Brasileña en la Universidade do Estado do Río de Janeiro (UERJ). Titular de beca de investigación em la institución pública financiadora CAPES. thayanevercosa@hotmail.com
} 
teatro Equilibrio Precario, a partir de diferentes y variadas formas de experimentación en el lenguaje teatral: el teatro de sombras, los objetos, el teatro callejero, entre otros.

Como punto de partida de esta entrevista, nos gustaría recordar una cita de Hacia una literatura sin adjetivos, en la que la escritora argentina María Teresa Andruetto cuestiona el papel de la ficción y destaca el sentido de "textos/mundos" como factor de subjetividad, identidad y alteridad:

\begin{abstract}
Un relato de ficción es por lo tanto un artificio, algo por su misma esencia liberado de su condición utilitaria, un texto en el que las palabras hacen otra cosa, han dejado de ser funcionales, como han dejado de serlo los gestos en el teatro, las imágenes en el cine, los sonidos en la música, para buscar a través de esa construcción algo que no existía, un objeto autónomo que se agrega a lo real. La ficción, cuya virtualidad es la vida, es un artificio cuya lectura o escucha interrumpe nuestras vidas y nos obliga a percibir otras vidas que ya han sido, que son pasado, puesto que se narran. Palabra que llega por lo que dice, pero también por lo que no dice, por lo que nos dice y por lo que dice de nosotros, todo lo cual facilita el camino hacia el asombro, la conmoción, el descubrimiento de lo humano particular, mundos imaginarios que dejan surgir lo que cada uno trae como texto interior y permiten compartir los texto/mundos personales con los texto/mundos de los otros (ANDRUETTO, 2012, p. 54-55; énfasis agregado).
\end{abstract}

Andruetto (2012) también advierte del riesgo de enfatizar el adjetivo "infantil" en la literatura, bajo pena de restringirlo a lo funcional, reduciéndolo a un conjunto de obras que no valoran la calidad estética o, incluso, de segregar a autores que, porque escriben para niños, no merecen ser leídos por adultos. Conscientes de todos estos prejuicios, optamos, precisamente, por iniciar las preguntas desde la perspectiva de la literatura infantil.

\title{
PALIMPSESTO
}

1) En el artículo "Configuración de ensambles intersemióticos en literatura infantil multimodal chilena: el discurso adulto articulado en el significado multimodal para niños", se presentan los resultados del Análisis del Discurso Multimodal a partir de un corpus de seis libros álbumes chilenos, un género narrativo multimodal que requiere, desde la perspectiva de la Lingüística Sistémica Funcional (Halliday, 2014) y la Semiótica Social (van Leeuwen, 2005; Kress y van Leeuwen, 2006; Painter, Martin y Unsworth, 2013), una lectura que involucra el modo imagen para acceder al significado general del texto. Destacando de la cita que inicia este apartado el hecho de que "un texto en el que las palabras hacen otra cosa, ya no son funcionales" (ANDRUETTO, 
2012, p. 54), la configuración de ensambles específicos a nivel de cada texto analizado en su trabajo ¿se puede atribuir al carácter estético del material seleccionado?

\section{CARMEN LUZ MATURANA}

Los ensambles multimodales dan cuenta del espacio semántico donde se combinan los significados de distintos sistemas semióticos. Es decir, los distintos modos semióticos y los significados que cada uno de ellos aporta se articulan para la realización del significado global. A partir de la evidencia del análisis de ensambles en literatura multimodal infantil chilena, puedo afirmar que la ontogénesis de la imagen propicia el ensamblaje intramodal. A diferencia del lenguaje verbal, que se instancia sólo a través del modo oral o el modo escrito, la imagen considera e integra otros modos semióticos en su realización material. Así, por ejemplo, el lenguaje de los ángulos de cámara, usado también en el cine y la fotografía, es un modo en sí mismo, y sus significados tienen un alcance global. Tal como plantea Rheindorf (2004), el modo ángulo de cámara empezó en el medio audiovisual del cine, se traspasó luego al medio impreso en la fotografía, y hoy opera de manera estable en cualquier medio que reproduzca el modo de la imagen, como por ejemplo el cómic, el libro álbum o la novela gráfica, entre otros géneros multimodales narrativos.

Los ensambles multimodales que articulan los sistemas visuales y verbales que se instancian en el material estudiado presentan tal variedad de combinaciones, que no es posible evidenciar un patrón único de estructuración interna. La evidencia del análisis muestra que los ensambles se organizan sólo respecto a la constitución intermodos, pero no lo hacen respecto a qué sistemas organizan multimodalmente en cada modo. Por ejemplo, se observa que los Participantes se construyen por medio de ensambles que conectan los sistemas verbales y visuales, aun cuando la configuración interna de esos ensambles varía según el texto analizado. Desde otra perspectiva de construcción, el análisis del color permite afirmar que éste opera como un modo cuando el creador tiene la intención de utilizarlo como tal. Si eso sucede, el color se inserta en la imagen y, por lo tanto, en los ensambles, aportando al significado de manera evidente. Sin embargo, habrá que analizar las paletas de color de cada ejemplar textual para abordar el significado, ya que no hay un significado único asociado a cada color. Este dependerá del análisis particular de cada texto analizado. En síntesis, el significado se articula en 
cada uno de los ensambles de manera dinámica. Esta organización interna es variable, debido al carácter estético del material estudiado, donde la creatividad y originalidad son componentes esenciales de los recursos, y donde se presentan distintos niveles de lectura. Como toda obra creativa, la literatura infantil de calidad presenta textos verbales y visuales que, en conjunto, se alejan de un carácter utilitario y unívoco.

\section{PALIMPSESTO}

2) ¿Cómo se relaciona el examen de la construcción semiótica del discurso multimodal con la alfabetización de los niños?

\section{CARMEN LUZ MATURANA}

Es determinantes para la alfabetización, ya que el modo visual no solo funciona como un andamiaje para la comprensión verbal, sino que en ocasiones opera como un lenguaje en sí mismo. En relación a la articulación de ambos modos para expresar relaciones de causa-efecto, el modo visual no siempre las representa explícitamente, por lo que se requiere para su compresión el desarrollo de habilidades lectoras de nivel superior, como las inferencias. Esta conexión posibilita también abordar conocimientos disciplinares, así como habilidades de inferencia intermodales para comprender el despliegue narrativo en géneros ficcionales. Me gustaría aclarar que no planteo de ninguna forma que el fin de la literatura infantil multimodal sea enfocada de manera utilitaria al currículum escolar. Por el contrario, la postura es que una vez abordado el componente estético, el material podría servir a objetivos educativos.

Es necesario, sin embargo, tener en consideración que las herramientas conceptuales no son las mismas en lingüística y semiótica que en educación. En este último caso, el foco es la utilización pedagógica de la multimodalidad. Desde esta perspectiva, el aporte que el análisis lingüístico y semiótico proporciona al ámbito de la formación de profesores se relaciona con la comprensión de que el lenguaje se articula multimodalmente y que el aprendizaje de la lectura es multidimensional. Por lo tanto, ésta se vincula con el desarrollo de habilidades vinculadas al modo verbal, como la comprensión y producción de géneros discursivos diversos, con la intención de potenciar las habilidades comunicativas, los repertorios semióticos y el razonamiento. 
El trabajo de sintetizar los resultados y adecuarlos a un lector vinculado al ámbito educativo, ya sea como estudiante de pedagogía o como docente en aula, es parte fundamental del trabajo del analista, desde mi perspectiva.

\section{PALIMPSESTO}

3) Considerando la afirmación de que "gran parte de los textos contemporáneos construyen sus mensajes de manera multimodal, por medio la articulación de los modos o lenguajes de la comunicación verbal - oral o escrita - con las imágenes" (MATURANA-ARANEDA, 2020, p. 666), ¿a qué otras conclusiones se puede llegar del estudio de los conjuntos intersemióticos en la literatura multimodal chilena?

\section{CARMEN LUZ MATURANA}

Los sistemas generales diseñados por Painter, Martin y Unswortt (2013) para el inglés operan de manera efectiva en el corpus chileno. Sin embargo, los grados de fineza de algunos varían. Por ejemplo, en relación al sistema de Diseño Gráfico, el corpus analizado presenta opciones más variadas para el rasgo del texto subsumido en la imagen que las que se observan el corpus en inglés. Estos resultados también se hacen extensivos a otros textos literarios multimodales latinoamericanos.

Asimismo, la utilización del color en el material chileno, pero también en el material latinoamericano, tiene un rol determinante para la narración. La observación del color a partir de ensambles multimodales permite afirmar que este opera como un modo cuando el creador tiene la intención de utilizarlo como tal. Si eso sucede, el color se inserta en la imagen y, por lo tanto, en los ensambles, aportando al significado de manera evidente. No solo se utiliza para establecer relaciones con la audiencia y los lectores, sino que configura mundos y articula la composición global del recurso. De esta forma, el color puede llegar a estar vinculado a la estructura narrativa. Al respecto, es apropiado tener en cuenta que los significados pertenecen a la cultura más que a modos semióticos específicos (KRESS Y VAN LEEUWEN, 2010). Por lo anterior, es imprescindible tener presente que los significados que son instanciados multimodalmente están cultural e históricamente situados. En el caso del corpus chileno, puede influir que la y los autores son también dibujantes, en la mayor parte de los textos. 


\section{PALIMPSESTO}

4) En cuanto a la autonomía en la producción textual, el artículo "Incidencia de la multimodalidad y la pedagogía de género en la escritura de Informes Descriptivos en segundo básico" (2021), publicado en coautoría con la investigadora Bárbara Gálvez Fredes, analiza la producción escrita de un grupo de 23 estudiantes de segundo básico, quienes son evaluados antes y después de un ciclo de enseñanza aprendizaje que abordó la escritura multimodal de un informe descriptivo. Nos gustaría conocer un poco más sobre esta experiencia y sobre los resultados de la incorporación de la pedagogía de género desde una perspectiva multimodal.

\section{CARMEN LUZ MATURANA}

Se trata de una experiencia realizada en un colegio de Estación Central, en la ciudad de Santiago de Chile. El sector donde se inserta el colegio es una población surgida a partir de tomas de terreno en los años 40 del siglo XX. En la actualidad, es una zona donde habita una gran cantidad de población migrante, con un importante número de familias haitianas. Además, el colegio presenta una tasa de estudiantes en situación de vulnerabilidad social, según los datos de organismos estatales.

El Ministerio de las Culturas fue la entidad que financió el proyecto, después de una adjudicación en un concurso público. El objetivo general del proyecto fue articular una propuesta de alfabetización multimodal como eje de una propuesta didáctica de desarrollo del lenguaje en la práctica escolar, para fomentar procesos de alfabetización efectivos vinculados a la lectura y escritura. Para esto, realizamos clases durante el año 2019 en segundo y tercero de primaria, en sesiones de 90 minutos en cada curso, una vez a la semana.

Los resultados más importantes tienen que ver con el desarrollo de la autonomía en el proceso de escritura en una sala de clases diversa, con grandes diferencias en el desempeño de sus integrantes. La incorporación de una perspectiva multimodal permitió siempre captar la atención de los participantes, incluso de los estudiantes que no sabían leer y escribir. De esta manera, la imagen posibilitó que todos participaran de las actividades desde un inicio. Posteriormente, ese interés inicial se canalizaba hacia el trabajo más específico con los estudiantes que requerían mayor apoyo en el ámbito del desarrollo del lenguaje escrito. Nunca nadie quedó excluido del trabajo, ya que la 
imagen no era accesoria, sino una parte fundamental de los géneros discursivos trabajados con los cursos. Para los estudiantes fue algo natural interesarse en leer y escribir, ya que el foco para ellos era poder desarrollar el género e incorporar el elemento verbal con el visual. La imagen fue el punto de entrada al desarrollo del género.

\section{PALIMPSESTO}

5) "La multimodalidad fue un elemento relevante, ya que permitió que no se sintiera excluido y que pudiera generar significados." (MATURANA-ARANEDA \& GÁLVEZFREDES, 2021, p. 35). El informe pedagógico informa que había tres estudiantes haitianos en el grupo que estaban adquiriendo el español como segunda lengua. Volviendo a las palabras de Andruetto (2012, p. 55) sobre compartir "textos / mundos personales con los textos / mundos de los demás", podría comentar la importancia del enfoque adoptado para construir el sentimiento de pertenencia y para la auto-estima de los estudiantes?

\section{CARMEN LUZ MATURANA}

Hay que destacar que el artículo que publicamos solo menciona a tres niños haitianos, ya que el análisis implicaba que cada estudiante debía haber estado presente en el pre y en el post test desde el inicio de cada una de las evaluaciones. Esta situación nos hizo excluir algunas muestras, aun cuando había mayor cantidad de niños haitianos en el curso. El ciclo de enseñanza aprendizaje de la pedagogía del género (Rose y Martin, 2012) plantea el desarrollo de secuencias didácticas en el área de lenguaje a partir de géneros discursivos. Esta secuencia consta de la deconstrucción explícita del género con los estudiantes. Posteriormente, se realiza una construcción conjunta con los escolares y, finalmente, el curso realiza la escritura individual del texto y se edita para su publicación dentro del contexto escolar. Esta última etapa involucra el trabajo docente con quienes requieran mayor apoyo pedagógico.

El enfoque didáctico permitió que nadie quedara fuera del trabajo desarrollado. Como se pudo trabajar con quienes tenían más dificultades de manera individual, los logros para ellos eran evidentes. Este hecho fue relevante para lograr el involucramiento durante todo el ciclo, ya que los estudiantes que no dominaban la lectura y escritura en español presentaban de manera general poca motivación para participar en las tareas 
desarrolladas durante la jornada escolar. La imagen fue una importante posibilidad para ellos de generar significados asociados a la tarea solicitada y, por lo tanto, de motivarse para trabajar en la actividad. Luego, el trabajo docente les permitía seguir trabajando con un andamiaje apropiado a su nivel de alfabetización.

\section{PALIMPSESTO}

6) En la introducción del trabajo con Andrea Gaete Pessaj, "Un recorrido a las formas animadas en la educación escolar y talleres: la mirada de las investigadoras" (2020), se afirma que "[e]l término multimodalidad (KRESS, VAN LEEUWEN, 2006) refleja la relación que se establece entre dos o más sistemas semióticos o lenguajes para la creación del significado. En concordancia con los postulados de Voloshinov (1986), la multimodalidad observa los signos sociales que se instancian en base a algún material, ya que los significados de la actividad semiótica social se cristalizan en la materialidad de los recursos." (p. 24). La investigación busca establecer vínculos entre las publicaciones realizadas por mujeres durante el siglo XX a la fecha, disponibles en el Centre de Recherche et de Documentation del Institut International de la Marionnette, relacionando el teatro de formas animadas (AMARAL, 1991) y la educación. ¿Concluimos que el vínculo entre multimodalidad y educación no es nada nuevo, entonces?

\section{CARMEN LUZ MATURANA}

La verdad es que no lo es. La imagen siempre ha estado en el trabajo escolar. La particularidad hoy es que contamos con categorías de análisis específicas para comprender cómo se articula el modo visual con el verbal para la generación de significados, en géneros discursivos pertenecientes a las distintas disciplinas, no solo al área del lenguaje. Desde esta perspectiva teórica, es interesante para el análisis discursivo observar cómo se contrastan y se relacionan el modo verbal y el modo visual en ensambles multimodales dentro de los géneros discursivos escolares.

Donde sí se observan cambios es en los énfasis que tiene la imagen dentro del contexto educativo. Inicialmente, el vínculo tiene un énfasis moralizante para desarrollar conductas "adecuadas" en los niños, como obediencia a los mandatos adultos y su correcta ejecución. No obstante, todos los materiales estudiados abordan la diversión en el trabajo como un elemento básico. El vínculo hacia el desarrollo del 
lenguaje se observa también durante todo el siglo $\mathrm{XX}$, sin embargo, gradualmente se incorpora una mirada más interdisciplinar.

\section{PALIMPSESTO}

7) Tu trayectoria profesional está ligada al teatro, ¿verdad? En la obra Ciencia y espetáculo (2013), organizada por María José Correa, Andrea Kottow y Silvana Vetö, hay un capítulo de su autoría "Entre magia, superstición y ciencia", que trata de los espectáculos con proyección óptica en Chile, entre 1829 y 1969. Menciona, entre otros temas, el hecho de que la mirada es una construcción social, cultural y tecnológica, no exenta de adoctrinamiento. ¿Es posible establecer una relación entre la elección de este título y su experiencia académica? Cuéntenos un poco sobre la investigación sobre el teatro de títeres y sombras en Chile.

\section{CARMEN LUZ MATURANA}

Ese artículo fue escrito con Catalina Donoso, investigadora y académica del Instituto de la Comunicación e Imagen de la Universidad de Chile. Efectivamente, planteamos que la mirada es una construcción social y está determinada, en última instancia, por los acercamientos que hayamos tenido a otras imágenes previamente. Lo que hoy nos parece inverosímil, o incluso divertido, de una película de inicios del siglo $\mathrm{XX}$, no tenía ese significado en ese momento, ya que nuestro conocimiento respeto a la técnica también ha evolucionado como espectadores. Kress y Van Leeuwen (2006) mencionan que la verdad es un constructo de la semiosis o asignación de sentido, ya que la realidad está en la mirada del espectador. Por ejemplo, mencionan que una imagen hiperrealista científica, que sobrepasa el modelo estándar socialmente dominante respecto de la representación visual, es percibida como alejado de lo "normal" e incluso como falsa, sin serlo.

En el caso de mi formación académica, esta se inicia en el ámbito de la lingüística y la literatura. Luego, los estudios de diseño teatral y el oficio del teatro me permitieron comprender en la práctica las teorizaciones lingüísticas y semióticas en relación al signo. Posteriormente, luego de 20 años trabajando escénicamente, retomé la formación académica en estudios de postgrado en lingüística y en semiótica, los que me permiten hoy trabajar con la imagen desde una perspectiva analítica, pero que no olvida nunca el trabajo con el material. Así, el color y la imagen no son para mí solo un ámbito 
de estudio, sino que llevo en mi mirada también mis propias vivencias con estos recursos que me permitieron crear significados.

En relación al teatro de sombras y títeres en Chile, es un lenguaje escénico que lleva siglos de presencia en el país. Incluyo también a los efectos ópticos de proyección, como las linternas mágicas y otros aparatos precinematográficos. Inicialmente, formando parte de juegos de entretención familiar y social. A partir del siglo XIX, se utilizaron en el ámbito del espectáculo escénico. En ese período, el discurso social predominante de la élite respecto de los efectos ópticos y físicos involucrados en los espectáculos de proyección visual pasó del rechazo inicial, por su supuesta vinculación con la magia y lo diabólico, hacia la tolerancia y la aceptación, relacionando el género con el humor. Después de la irrupción del cinematógrafo, a inicios del siglo XX, los recursos ópticos que habían sido usados teatralmente son incorporados a este nuevo arte. El discurso oficial referido a estos efectos ópticos tomó entonces un nuevo giro hacia lo científico, como una explicación a los fenómenos de la física implícitos en los resultados mágicos, abandonado toda consideración peyorativa al respecto. Desde la segunda mitad del siglo XX hasta la actualidad, es uno más de los lenguajes utilizados en la escenificación.

El teatro de títeres contemporáneo se ha valido de diferentes códigos visuales antiguos para su realización. Uno de ellos ha sido el Teatro de Sombras. Se retoman así corrientes antiguas del teatro visual, de la comedia de magia, del guiñol, entre otros. Si bien estos lenguajes llevan siglos de vigencia en nuestro país, han sido escasamente estudiados. Hoy se refractan y concretan en grupos que rompen el paradigma del texto. A cambio, ocupan múltiples lenguajes escénicos y una dramaturgia no convencional, vinculada principalmente a la narración escénica visual.

\section{Referencias}

ANDRUETTO, María Teresa. Por uma literatura sem adjetivos. São Paulo: Pulo do Gato, 2012.

MATURANA, Carmen Luz. Configuración de ensambles intersemióticos en literatura infantil multimodal chilena: el discurso adulto articulado en el significado multimodal para niños. Discurso \& Sociedad. [S. l.], v. 3, n.14, p. 661-682, 2020. Disponível em: 
http://www.dissoc.org/ediciones/v14n03/DS14\%283\%29Maturana.html. Acesso em 01 dez. 2021.

MATURANA, Carmen Luz. History of Chilean Theatre and Metaphoric use of Puppetry. In: JURKOWSKI, Henryk; RADONJIC, Miroslav (Ed.). Theatre for Children: artistic phenomenon, a collection of papers. Vol. 4. Subotica: Open University Subotica, 2013. p. 97-114.

MATURANA, C. L.; GAETE, A. Un recorrido a las formas animadas en la educación escolar y talleres: la mirada de las investigadoras. Móin-Móin - Revista de Estudos sobre Teatro de Formas Animadas, Florianópolis, v. 2, n. 23, p. 022-043, 2020. DOI: 10.5965/2595034702232020022. Disponível em: https://www.revistas.udesc.br/index.php/moin/article/view/18597. Acesso em $1 \mathrm{dez}$. 2021.

MATURANA, C. L..; GÁLVEZ-FREDES, B. Incidencia de la multimodalidad y la pedagogía de género en la escritura de Informes Descriptivos en segundo básico. Íkala Revista de Lenguaje y Cultura. [S. l. $]$ v. 1, n. 26, p. 19-39, 2021. DOI: 10.17533/udea.ikala.v26n01a04. Disponível em: https:/uccl.academia.edu/CarmenMaturana. Acesso em 20 out. 2021. 


\title{
Terá a magia suscitado a pesquisa? Entrevista sobre Análise do Discurso Multimodal com a professora e pesquisadora Carmen Luz Maturana
}

\author{
Carmen Luz Maturana ${ }^{\mathrm{i}}$ \\ Entrevistadores: \\ Ana Paula Macri ${ }^{\mathrm{ii}}$ \\ Lais Alves ${ }^{\mathrm{iii}}$ \\ Thayane Verçosa ${ }^{\text {iv }}$
}

Terá a magia suscitado a pesquisa? Nesta edição, a Palimpsesto convida Carmen

Luz Maturana, designer de teatro e linguista, para uma conversa acerca da multimodalidade. Doutora em Linguística pela Universidade Católica do Chile, Professora assistente adjunta na mesma instituição, a pesquisadora integra a equipe docente do Programa de Leitura e Escrita Acadêmica (PLEA) da Faculdade de Letras UC. Suas áreas de interesse incluem a Análise do Discurso Multimodal e a Semiótica Educativa. Liderou o projeto "Incidência da multimodalidade em leitura e escrita na Educação Básica", financiado pelo Ministério das Culturas e das Artes do Chile (20192020). Entre suas investigações, incluem-se o teatro de sombras e os espetáculos teatrais da era pré-cinematográfica. Iniciou, em 1994, a companhia de teatro Equilibrio Precário a partir de diferentes e variadas formas de experimentação na linguagem teatral, como teatro de sombras, objetos, teatro de rua, entre outros.

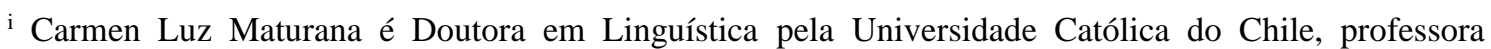
assistente adjunta na Universidade Católica do Chile, integra a equipe docente do Programa de Leitura e Escrita Acadêmica (PLEA) da Faculdade de Letras UC. Suas áreas de interesse incluem a Análise do Discurso Multimodal e a Semiótica Educativa.

ii Mestranda em Língua Portuguesa na Universidade do Estado do Rio de Janeiro (UERJ), especialista em Língua Portuguesa pelo Liceu Literário. anapaulamacri@gmail.com

iii Mestranda em Teoria da Literatura e Literatura Comparada pela Universidade do Estado do Rio de Janeiro (UERJ). Bolsista CAPES. 1ais.alvessouza@yahoo.com.br

iv Doutoranda em Literatura Brasileira pela Universidade do Estado do Rio de Janeiro. Bolsista Capes. thayanevercosa@hotmail.com
} 
Como ponto de partida para esta entrevista, aludimos à obra Por uma literatura sem adjetivos, em que a escritora argentina María Teresa Andruetto, ao questionar o papel da ficção, põe em destaque o sentido de "textos/mundos" como fator de subjetividade, de identidade e de alteridade:

\begin{abstract}
Uma narrativa ficcional é, portanto, um artifício, algo, por sua própria essência, liberado de sua condição utilitária, um texto no qual as palavras fazem outra coisa, deixaram de ser funcionais, como deixaram de sê-lo os gestos no teatro, as imagens no cinema, os sons na música, para buscar através dessa construção, algo que não existia, um objeto autônomo que se agrega ao real. A ficção, cuja virtualidade é a vida, é um artifício cuja leitura ou escuta interrompe nossas vidas e nos obriga a perceber outras vidas que já foram, que são passado, posto que são narradas. Palavra que chega pelo que diz, mas também pelo que não diz, pelo que nos diz e pelo que diz de nós, tudo o que facilita o caminho até o assombro, a comoção, o descobrimento do humano particular, mundos imaginários que deixam surgir o que cada um traz como texto interior e permitem compartilhar os textos/mundos pessoais com os textos/mundos dos outros (ANDRUETTO, 2012, p. 54-55; grifos da autora).
\end{abstract}

Andruetto (2012) também alerta para o risco de se colocar em relevo o adjetivo "infantil" na literatura, sob pena de restringi-la ao funcional, de reduzi-la a um conjunto de obras que não prezam pela qualidade estética ou, ainda, de segregar autores que, por escreverem para crianças, não mereçam ser lidos por adultos. Sabendo de todos os preconceitos que a circundam, optamos, justamente, por iniciar as perguntas pela perspectiva da literatura infantil.

\title{
PALIMPSESTO
}

1) No artigo "Configuração de padrões intersemióticos na literatura infantil multimodal chilena: o discurso adulto articulado ao significado multimodal para crianças", apresentam-se os resultados da Análise Multimodal do Discurso a partir de um corpus de seis livros álbuns chilenos, gênero narrativo multimodal que requer, a partir da perspectiva da Lingüística Sistêmica Funcional (Halliday, 2014) e da Semiótica Social (van Leeuwen, 2005; Kress e van Leeuwen, 2006; Painter, Martin e Unsworth, 2013), uma leitura que envolva o modo da imagem para acessar o significado global do texto. Destacando da citação que dá início a esta seção o fato de que "um texto no qual as palavras fazem outra coisa, deixaram de ser funcionais" (ANDRUETTO, 2012, p. 54), a configuração de padrões específicos ao nível de cada texto analisado em seu trabalho pode ser atribuída ao caráter estético do material selecionado? 


\section{CARMEN LUZ MATURANA}

Os padrões multimodais são responsáveis pelo espaço semântico onde se combinam os significados de sistemas semióticos distintos. Isto é, os diferentes modos semióticos e os significados que cada um deles traz articulam-se para a realização do significado global. A partir da evidência da análise de padrões da literatura multimodal infantil chilena, posso afirmar que a ontogênese da imagem propicia o padrão intramodal. Diferentemente da linguagem verbal, que se realiza apenas através do modo oral ou do modo escrito, a imagem considera e integra outros modos semióticos em sua realização material. Assim, por exemplo, a linguagem dos ângulos da câmera, presente também no cinema e na fotografia, é um modo em si mesmo, e os seus significados têm um alcance global. Tal como propõe Rheindorf (2004), o modo ângulo da câmera começou no meio audiovisual do cinema, foi logo transferido para o meio impresso na fotografia e hoje opera de forma estável em qualquer meio que reproduza o modo da imagem, como, por exemplo, a história em quadrinhos, o livro álbum ou o romance gráfico, entre outros gêneros multimodais narrativos.

Os padrões multimodais que articulam os sistemas visuais e verbais presentes no material estudado apresentam tamanha variedade de combinações, que não é possível evidenciar um padrão único de estruturação interna. A evidência da análise mostra que os padrões se organizam apenas a respeito da constituição intermodal, mas não o fazem com relação a quais sistemas se organizam multimodalmente em cada modo. Por exemplo, observa-se que os Participantes se constroem por meio de padrões que conectam os sistemas verbais e visuais, mesmo quando a configuração interna desses padrões varia segundo o texto analisado. A partir de outra perspectiva de construção, a análise de uma cor permite afirmar que esta opera como um modo quando o criador tem a intenção de utilizá-la como tal. Se isso acontece, a cor se insere na imagem e, portanto, nos padrões, contribuindo para o significado de maneira evidente. No entanto, será preciso analisar as paletas de cores de cada exemplar textual para abordar o significado, já que não há um significado único associado a cada cor. Este dependerá da análise particular de cada texto estudado. Em suma, o significado se articula em cada um dos padrões de maneira dinâmica. Esta organização interna varia, devido ao caráter estético do material estudado, no qual a criatividade e a originalidade são componentes essenciais dos recursos, nos quais se apresentam diferentes níveis de leitura. Como toda 
obra criativa, a literatura infantil de qualidade apresenta textos verbais e visuais que, em conjunto, se afastam de um caráter utilitário e unívoco.

\section{PALIMPSESTO}

2) De que forma o exame da construção semiótica do discurso multimodal se relaciona com a alfabetização infantil?

\section{CARMEN LUZ MATURANA}

É determinante para a alfabetização, já que o modo visual não funciona sozinho como um andaime para a compreensão verbal, mas às vezes funciona como uma linguagem em si mesma. Em relação à articulação de ambos os modos para expressar as relações de causa-efeito, o modo visual nem sempre as representa explicitamente, uma vez que é necessário para a sua compreensão o desenvolvimento de habilidades de leitura avançadas, como as inferências. Esta conexão possibilita também abordar conhecimentos disciplinares, assim como habilidades de inferência intermodais para compreender o desenvolvimento narrativo em gêneros ficcionais. Gostaria de esclarecer que não proponho de forma alguma que o fim da literatura infantil multimodal seja abordado de maneira utilitária no currículo escolar. Pelo contrário, a posição é a de que, uma vez abordado o componente estético, o material poderia servir a propósitos educacionais.

É preciso, no entanto, considerar que as ferramentas conceituais não são as mesmas tanto na linguística e na semiótica quanto na educação. Neste último caso, o foco é a utilização pedagógica da multimodalidade. Nesta perspectiva, a contribuição que a análise linguística e semiótica oferece ao campo da formação de professores se relaciona à compreensão de que a linguagem se articula multimodalmente, e a percepção de que a aprendizagem da leitura é multidimensional. Portanto, esta se relaciona ao desenvolvimento de habilidades ligadas ao modo verbal, como a compreensão e a produção de gêneros discursivos diversos, com a intenção de ampliar as habilidades comunicativas, os repertórios semióticos e o raciocínio. O trabalho de sintetizar os resultados e adequá-los a um leitor da área de educação, seja como aluno de pedagogia ou professor, é parte fundamental do trabalho do analista, na minha opinião. 


\section{PALIMPSESTO}

3) Considerando a afirmação de que "grande parte dos textos contemporâneos constroem as suas mensagens de forma multimodal, por meio da articulação dos modos ou linguagens da comunicação verbal - oral ou escrita - com as imagens" (MATURANA-ARANEDA, 2020, p. 666), a que outras conclusões se podem ascender a partir do estudo dos conjuntos intersemióticos na literatura multimodal chilena?

\section{CARMEN LUZ MATURANA}

Os sistemas gerais desenhados por Painter, Martin e Unswortt (2013) para o inglês atuam de forma efetiva no corpus chileno, porém, os graus de fineza de alguns variam. Por exemplo, em relação ao sistema de Desenho Gráfico, o corpus analisado apresenta opções mais variadas para o recurso do texto subsumido na imagem do que as que se observam no corpus em inglês. Estes resultados também se estendem a outros textos literários multimodais latino-americanos.

Além do mais, a utilização de cor no material chileno, mas também no material latino-americano, tem um papel determinante para a narração. A observação de cor a partir dos padrões multimodais permite afirmar que este opera como um modo quando o criador tem a intenção de utilizá-lo como tal. Se isso acontece, a cor se insere na imagem e, portanto, nos padrões, contribuindo para o significado de forma óbvia. Não serve apenas para estabelecer relações com a audiência e com os leitores, mas também configura mundos e articula a composição global do recurso. Desta forma, a cor pode chegar a se vincular à estrutura narrativa. A este respeito, é apropriado considerar que os significados pertencem à cultura mais do que a modos semióticos específicos (KRESS Y VAN LEEUWEN, 2010), portanto, é imprescindível lembrar que os significados que são multimodalmente instanciados estão cultural e historicamente situados. No caso do corpus chileno, pode influenciar o fato de que os autores são também ilustradores, na maior parte dos textos.

\section{PALIMPSESTO}


4) Em relação à autonomia na produção textual, o artigo "Incidência da multimodalidade e pedagogia de gênero na escrita de Informes Descritivos no Ensino Básico" (2021), publicado em coautoria com a pesquisadora Bárbara Gálvez Fredes, analisa a produção escrita de um grupo de 23 estudantes de Ensino Básico, que são avaliados antes e depois de um ciclo de ensino e aprendizagem que abordou a escrita multimodal de um informe descritivo. Gostaríamos de saber um pouco mais sobre esta experiência e sobre os resultados da incorporação da pedagogia de gênero a partir de uma perspectiva multimodal.

\section{CARMEN LUZ MATURANA}

Trata-se de uma experiência realizada em um colégio da Estação Central, na cidade de Santiago do Chile. O setor onde a escola está inserida é uma população surgida a partir de ocupações de terrenos nos anos 1940. Atualmente, é uma área onde vive grande parte da população migrante, com um número significativo de famílias haitianas. Além disso, o colégio apresenta um índice de alunos em situação de vulnerabilidade social, segundo dados de órgãos estatais.

O Ministério das Culturas do Chile foi a entidade que financiou o projeto após uma premiação em um concurso público. O objetivo geral do projeto era articular uma proposta de alfabetização multimodal como eixo de uma proposta didática para o desenvolvimento da linguagem na prática escolar, a fim de promover processos de alfabetização eficazes ligados à leitura e à escrita. Para esse fim, realizamos aulas durante o ano de 2019 com os segundo e terceiro anos do Ensino Fundamental, em sessões de 90 minutos de aula, uma vez por semana.

Os resultados mais importantes têm a ver com o desenvolvimento da autonomia no processo de escrita em uma sala de aula diversificada, com grandes diferenças no desempenho de seus integrantes. A incorporação de uma perspectiva multimodal sempre chamou a atenção dos participantes, mesmo dos estudantes que não sabiam ler e escrever. Dessa forma, a imagem permitiu que todos participassem das atividades desde o início. Posteriormente, esse interesse inicial foi canalizado para trabalhos mais específicos com estudantes que precisavam de mais apoio na área de desenvolvimento da linguagem escrita. Ninguém jamais foi excluído do trabalho, pois a imagem não era um acessório, mas uma parte fundamental dos gêneros discursivos trabalhados nos cursos. Era natural que os estudantes se interessassem pela leitura e pela escrita, já que o 
foco, para eles, era poder desenvolver o gênero e incorporar o elemento verbal ao visual. A imagem foi o ponto de partida para o desenvolvimento do gênero.

\section{PALIMPSESTO}

5) "A multimodalidade foi um elemento relevante, já que permitiu que não se sentisse excluído e que produzisse significados" (MATURANA-ARANEDA \& GÁLVEZFREDES, 2021, p. 35). O relato pedagógico informa que havia no grupo três alunos haitianos em fase de aquisição do espanhol como segunda língua. Retomando as palavras de Andruetto (2012, p. 55) a respeito do compartilhamento "dos textos/mundos pessoais com os textos/mundos dos outros", poderia comentar a importância da abordagem empreendida para a construção do sentimento de pertencimento e para a autoestima dos estudantes?

\section{CARMEN LUZ MATURANA}

Deve-se destacar que o artigo que publicamos menciona apenas três crianças haitianas, visto que a análise implicava que cada estudante deveria ter estado presente no pré e no pós-teste, desde o início de cada uma das avaliações. Essa situação nos levou a excluir algumas amostras, embora houvesse mais crianças haitianas na turma. $\mathrm{O}$ ciclo de ensino-aprendizagem da pedagogia de gênero (ROSE \& MARTIN, 2012) propõe o desenvolvimento de sequências didáticas na área da linguagem, baseadas em gêneros discursivos. Isso consiste na desconstrução explícita do gênero com os estudantes. Posteriormente, foi realizada uma construção conjunta com os alunos e, finalmente, o curso estimulou a redação individual do texto, editando-o para publicação dentro do contexto escolar. Essa última etapa envolvia o trabalho dos professores com aqueles que precisavam de um apoio pedagógico maior.

$\mathrm{O}$ enfoque didático permitiu que ninguém fosse deixado de fora do trabalho. Como foi possível trabalhar de forma individual com aqueles que tinham mais dificuldades, para eles, as conquistas foram evidentes. Esse fato foi relevante no que se refere ao envolvimento dos alunos durante todo o ciclo, pois aqueles que não eram proficientes em leitura e escrita em espanhol geralmente não se sentiam muito motivados a participar das tarefas desenvolvidas durante a jornada escolar. 


\section{PALIMPSESTO}

6) Na introdução do trabalho em conjunto com Andrea Gaete Pessaj, "Um passeio pelas formas animadas na educação escolar e nas oficinas: o olhar das pesquisadoras" (2020), afirma-se que "[o] termo multimodalidade (KRESS, VAN LEEUWEN, 2006) reflete a relação estabelecida entre dois ou mais sistemas semióticos ou linguagens para a criação de significado [e que], de acordo com os postulados de Voloshinov (1986), observa os signos sociais que são instanciados com base em algum material, uma vez que os significados da atividade semiótica social se cristalizam na materialidade dos recursos" (p. 24). A investigação empreendida busca estabelecer vínculos entre as publicações realizadas por mulheres durante o século XX até o momento, disponíveis no Centre de Recherche et de Documentation del Institut International de la Marionnette, relacionando o teatro de formas animadas (AMARAL, 1991) e a educação. Conclui-se que o vínculo entre multimodalidade e educação não é nada recente, então?

\section{CARMEN LUZ MATURANA}

A verdade é que não. A imagem sempre esteve presente no trabalho escolar. A particularidade hoje é que temos categorias específicas de análise para entender como o modo visual é articulado com o verbal para a formação de significados em gêneros discursivos pertencentes a diferentes disciplinas, não somente à área da linguagem. A partir dessa perspectiva teórica, é interessante para a Análise do Discurso observar como os modos verbal e visual contrastam-se e se relacionam em conjuntos multimodais dentro dos gêneros discursivos escolares.

Onde se observam mudanças é na ênfase da imagem dentro do contexto educacional. Inicialmente, a ligação tem uma ênfase moralizadora no desenvolvimento de comportamentos "adequados" nas crianças, tais como obediência às ordens dos adultos e suas devidas execuções, entretanto, todos os materiais estudados abordam a diversão na tarefa como um elemento básico. A ligação com o desenvolvimento da linguagem também é observada ao longo de todo o século XX, no entanto, um olhar mais interdisciplinar foi gradualmente incorporado.

\section{PALIMPSESTO}

7) Sua trajetória profissional está ligada ao teatro, correto? Na obra Ciencia y espetáculo (2013), organizada por Maria José Correa, Andrea Kottow e Silvana Vetö, há um 
capítulo de sua autoria, "Entre a magia, a superstição e a ciência", que trata dos espetáculos com projeção ótica no Chile, entre 1829 e 1969. Nele, menciona-se, dentre outros tópicos, o fato de o olhar ser uma construção social, cultural e tecnológica, não isenta de doutrinamento. É possível estabelecer uma relação entre a escolha desse título e sua vivência acadêmica? Conte-nos um pouco sobre a pesquisa a respeito de teatro de marionetes e de sombras no Chile.

\section{CARMEN LUZ MATURANA}

Esse artigo foi escrito com a Catalina Danoso, pesquisadora e acadêmica do Instituto de Comunicação e Imagem da Universidade do Chile. De fato, argumentamos que o olhar é uma construção social e, em última instância, é determinado pelas abordagens que empregamos anteriormente em relação a outras imagens. O que hoje achamos inverossímil, ou mesmo engraçado, em um filme do início do século XX, não era entendido dessa forma na época, uma vez que nosso conhecimento da técnica [cinematográfica] também evoluiu como espectadores. Kress e Van Leeuwen (2006) mencionam que a verdade é uma construção semiótica ou uma atribuição de sentido, já que a realidade está no olhar do espectador. Eles mencionam, por exemplo, que uma imagem científica hiper-realista, que excede o modelo padrão socialmente dominante de representação visual, é percebida como distante do "normal" e até mesmo falsa, sem que ela o seja. Minha formação acadêmica teve início nas áreas da Linguística e da Literatura. Mais tarde, os estudos de design teatral e a arte do teatro me permitiram compreender na prática as teorizações linguísticas e semióticas em relação ao signo. Posteriormente, após vinte anos de trabalho cênico, retomei minha formação acadêmica com uma pós-graduação em Linguística e Semiótica, o que hoje me permite trabalhar com a imagem a partir de uma perspectiva analítica, mas sem nunca esquecer o trabalho com o material. Assim, cor e imagem não são apenas um campo de estudo para mim: também carrego em meu olhar minhas próprias experiências com esses recursos que me permitiram criar significados.

Em relação aos teatros de sombras e marionetes no Chile, essa é uma linguagem cênica presente no país há séculos. Também incluo os efeitos de projeção ótica, como lanternas mágicas e outros aparelhos pré-cinematográficos, no início, como parte de jogos de entretenimento familiar e social. A partir do século XIX, eles passaram a ser utilizados no campo do espetáculo teatral. O discurso social predominante da elite sobre os efeitos óticos e físicos envolvidos nos espetáculos de projeção visual mudou de uma 
rejeição inicial — devido a uma suposta ligação com a magia e o diabólico — para a tolerância e a aceitação, ligando o gênero ao humor. Após o advento do cinematógrafo no início do século XX, os recursos ópticos utilizados teatralmente foram incorporados a essa nova forma de arte. O discurso oficial referente a esses efeitos óticos deu, então, uma nova guinada em direção ao científico, como uma explicação dos fenômenos da física implícitos nos resultados mágicos, sendo abandonada toda consideração pejorativa a esse respeito. Desde a segunda metade do século XX até os dias de hoje, é mais uma das linguagens utilizadas na encenação.

O teatro de marionetes contemporâneo tem feito uso de diferentes códigos visuais antigos em sua realização. Um deles é o teatro de sombras. Dessa forma, as antigas correntes do teatro visual, da comédia de magia, da fantochada, entre outras, são retomadas. Embora essas linguagens estejam em uso no Chile há séculos, elas foram pouco estudadas. Hoje, são refratadas e concretizadas em grupos que quebram o paradigma do texto. Em troca, utilizam múltiplas linguagens cênicas e uma dramaturgia não convencional, principalmente ligada à narração cênica visual.

\section{Referências}

ANDRUETTO, María Teresa. Por uma literatura sem adjetivos. São Paulo: Pulo do Gato, 2012.

MATURANA, Carmen Luz. Configuración de ensambles intersemióticos en literatura infantil multimodal chilena: el discurso adulto articulado en el significado multimodal para niños. Discurso \& Sociedad. [S. l.], v. 3, n.14, p. 661-682, 2020. Disponível em: http://www.dissoc.org/ediciones/v14n03/DS14\%283\%29Maturana.html. Acesso em 01 dez. 2021.

MATURANA, Carmen Luz. History of Chilean Theatre and Metaphoric use of Puppetry. In: JURKOWSKI, Henryk; RADONJIC, Miroslav (Ed.). Theatre for Children: artistic phenomenon, a collection of papers. Vol. 4. Subotica: Open University Subotica, 2013. p. 97-114.

MATURANA, C. L.; GAETE, A. Un recorrido a las formas animadas en la educación escolar y talleres: la mirada de las investigadoras. Móin-Móin - Revista de Estudos sobre Teatro de Formas Animadas, Florianópolis, v. 2, n. 23, p. 022-043, 2020. DOI: 10.5965/2595034702232020022. Disponível em: https://www.revistas.udesc.br/index.php/moin/article/view/18597. Acesso em $1 \mathrm{dez}$. 2021. 
MATURANA, C. L..; GÁLVEZ-FREDES, B. Incidencia de la multimodalidad y la pedagogía de género en la escritura de Informes Descriptivos en segundo básico. Íkala Revista de Lenguaje y Cultura. $[S$. l. $]$ v. 1, n. 26, p. 19-39, 2021. DOI: 10.17533/udea.ikala.v26n01a04. Disponível em: https://uccl.academia.edu/CarmenMaturana. Acesso em 20 out. 2021. 